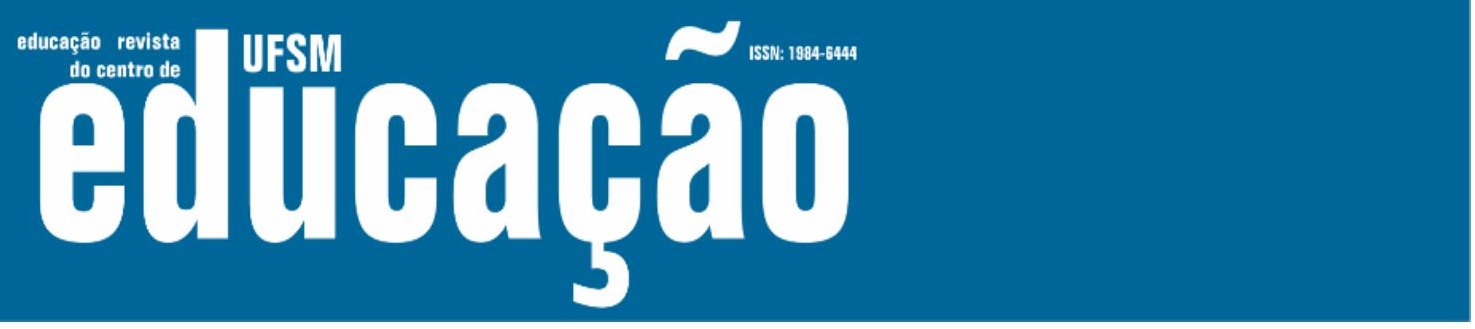

ISSN: 1984-6444 | http://dx.doi.org/10.5902/1984644461311

\title{
A complementaridade entre educação (formal, não formal e informal) e (auto, hetero e eco) formação: uma discussão a partir de autobiografias
}

La complementariedad entre educación (formal, no-formal e informal) e (auto, hetero y eco) formación: una discusión basada en autobiografías

The complementarity between education (formal non-formal and informal) and (self, hetero and eco) development: a discussion based on autobiographies

Paula Guimarães

Instituto de Educação, Universidade de Lisboa. Lisboa, Portugal. pguimaraes@ie.ulisboa.pt - http://orcid.org/0000-0002-2197-1004

Clarisse Faria-Fortecoëf

Universidade Paris 8, laboratoire Experice EA 3971. Paris, França.

clarisse.fariafortecoef@gmail.com - https://orcid.org/0000-0002-1810-1868

Recebido em 05 de outubro de 2020

Aprovado em 04 de janeiro de 2021

Publicado em 30 de março de 2021

\section{RESUMO}

Este texto inscreve-se no debate sobre o valor da experiência e das aprendizagens que desta decorrem, tendo como campo teórico a educação de adultos. Nele discutese a articulação entre as modalidades de educação formal, não formal e informal. Esta relação torna-se coerente nas biografias de sujeitos inscritas em contextos históricos específicos. Esta articulação relaciona-se com a necessária ligação entre a auto, hetero e ecoformação, quando se discutem aprendizagens desenvolvidas. Depois de uma discussão de caráter teórico, são analisadas duas autobiografias que se inscrevem no contexto da emigração portuguesa em França, nas quais os sujeitos relatam momentos-chave de educação e formação. Este debate permite responder à questão: como é que a educação formal, não formal e informal, assim como a auto, a hetero e a ecoformação se traduzem em aprendizagens? A análise de conteúdo é a técnica de discussão de dados usada. A interpretação dos dados coletados enfatiza a circunstância de a educação e a formação, resultantes de dinâmicas individuais e coletivas, permitirem desenvolver aprendizagens que enfatizam saber aprender, saber compreender e saber projetar-se.

Palavras-chave: educação; formação; autobiografia; iniciativa individual; educação de adultos 


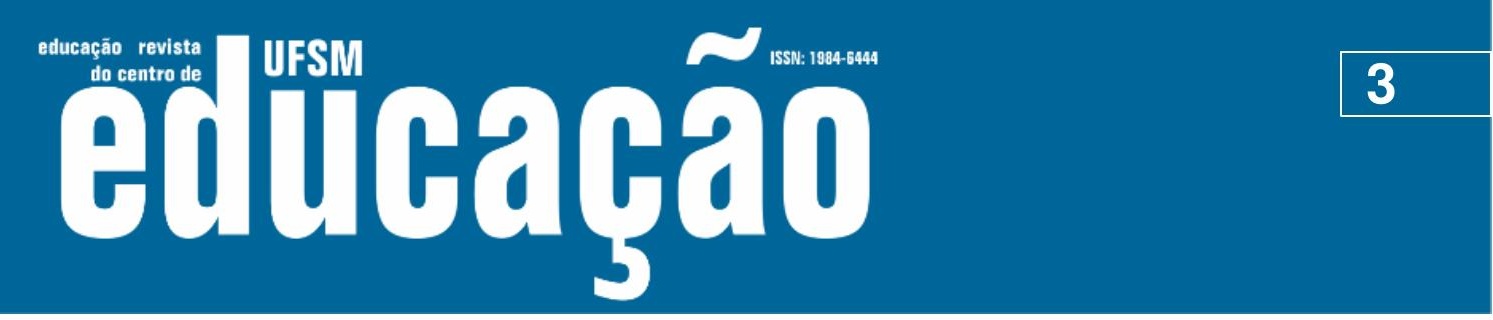

ISSN: 1984-6444 | http://dx.doi.org/10.5902/1984644461311

\section{Introdução}

O conceito de educação de adultos proposto pela UNESCO, em 1976 (UNESCO, 1977), retomado em 1997, por ocasião da V CONFINTEA (UNESCO, 1998), e em 2015 (UNESCO, 2016), assentou numa definição abrangente, contemplando uma diversidade de iniciativas, de formas e de práticas, de tempos e de espaços nos quais os sujeitos se educam e se formam ao longo da vida. Foi no quadro da educação permanente (FAURE ET AL., 1981) que esta definição de educação de adultos inicialmente se impôs, favorecendo também a aceitação de que a experiência se apresenta como uma poderosa fonte e um importante recurso para o desenvolvimento de novas aprendizagens. Nesta ordem de ideias, a dimensão educativa e formativa da vida resulta dos efeitos produzidos pelas experiências individuais e coletivas dos sujeitos, estando estes efeitos na origem de mudanças mais ou menos permanentes de comportamentos e atitudes, suportadas pelo desenvolvimento de aprendizagens diversas. É a partir destas aprendizagens que outras surgem. Por este motivo, Canário argumenta que "o património experiencial de cada um representa o recurso mais importante para a realização de novas aprendizagens" (CANÁRIO, 2006, p. 198), sendo estas centrais para a formação dos sujeitos. Neste artigo argumenta-se que as modalidades de educação formal, não formal e informal (PALHARES, 2009), ganham coerência nas biografias dos sujeitos, nomeadamente quando estes refletem sobre as suas experiências de vida inseridas em contextos históricos específicos. Defende-se também que a auto, hetero e ecoformação (PINEAU, 1988) são polos complementares e relacionados com as modalidades educativas atrás indicadas.

Num primeiro momento, este artigo inclui uma breve análise de caráter teórico sobre os conceitos de educação formal, não formal e informal e de auto, hetero e ecoformação. Depois de algumas notas metodológicas, estes conceitos são usados na análise de duas autobiografias que se constroem no contexto da emigração portuguesa em França, na segunda metade do século XX (GUIMARÃES \& FARIAFORTECOËF, 2013). Na discussão destas narrativas, procura-se destacar 


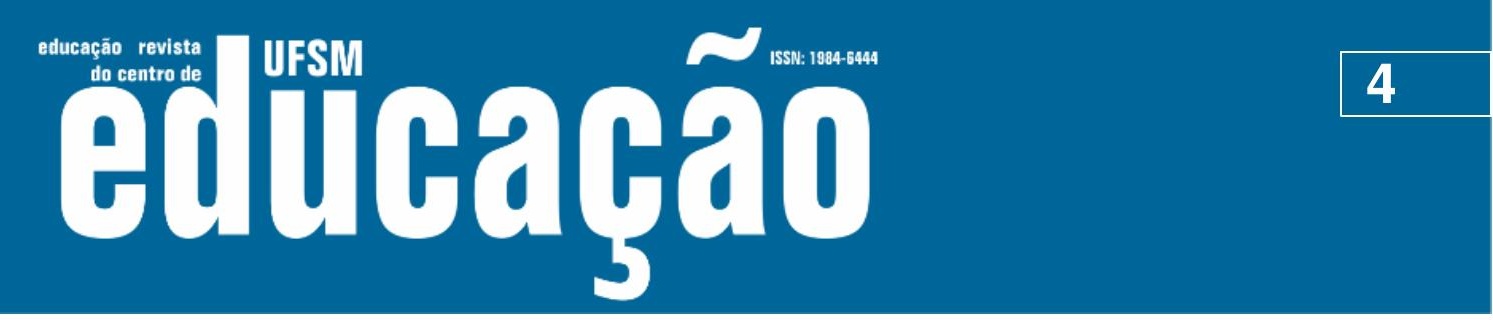

ISSN: 1984-6444 | http://dx.doi.org/10.5902/1984644461311

momentos-chave de educação (formal, não formal e informal) e (auto, hetero e eco) formação, assim como a interligação entre os mesmos.

\section{Educação (formal, não formal e informal) e (auto, hetero e eco) formação}

A valorização da experiência e a consequente reinterpretação dos percursos educativos dos adultos propostas pela definição de educação de adultos da UNESCO (1977 e 2016) traduziu a importância atribuída às modalidades educativas que se prolongam pela vida e ocorrem em contextos e momentos muito diversos. A relevância atribuída a espaços e tempos não escolares para aprender resultou de uma forte crítica à escola e da crise que autores como Coombs (1976) diagnosticaram a esta organização. Nesta linha de ideias, Lima et al. (1988), Canário (2006) e Palhares (2009), entre outros, identificam diferentes modalidades educativas: i) a educação formal, que possui como referência a escola e o ensino ministrado nesta organização, em propostas educativas marcadas pela intencionalidade, isto é, concebidas para concretizar certas finalidades, com tempos e espaços previamente definidos, atores que detêm papéis específicos, formas de avaliação frequentemente quantificáveis, etc.; ii) a educação não formal, baseada em tempos e espaços de aprendizagem diversos, assim como regras, conteúdos, métodos pedagógicos, etc., diferenciados, em que a participação dos variados atores possui um caráter sobretudo voluntário; e iii) a educação informal, que contempla situações não intencionais, pouco ou nada organizadas, programadas ou estruturadas, a partir das quais é possível desenvolver aprendizagens.

Estas modalidades não são mutuamente exclusivas, nem tão pouco se encontram em clara oposição ou separadas por fronteiras estanques. Diferentes autores destacam a complementaridade entre as mesmas (COOMBS, 1976; LIMA ET AL.,1988; PALHARES, 2009; ROGERS, 2014). Esta característica esbate as fronteiras entre a educação formal, que torna tendencialmente hegemônicas certas formas de ensinar e aprender, nomeadamente através da generalização do modelo 


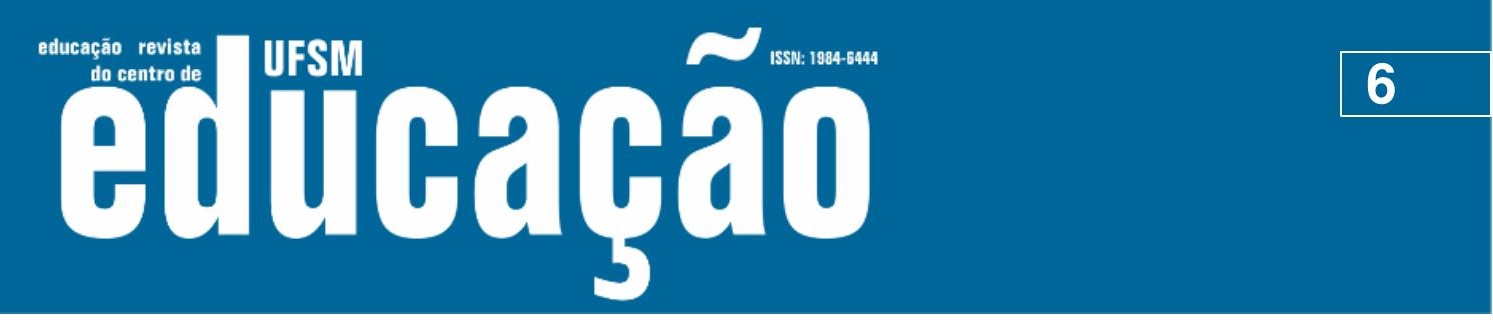

ISSN: 1984-6444 | http://dx.doi.org/10.5902/1984644461311

Leva ainda a que cada pessoa se diferencie das outras, enquanto permite que se realize uma aproximação sobre o próprio sujeito e relativamente a outros. Favorece igualmente a reflexão sobre si e sobre o que rodeia cada um. Facilita processos de autonomização e de emancipação. Estimula o esforço de autoformar-se. Seguindo esta ordem de ideias, Galvani defende que

o autos é uma expressão de duplo sentido. Pode ser visto como um fenómeno de reprodução, de repetição do idêntico, de auto-reprodução da espécie. Mas é igualmente importante sublinhar que o autos é uma representação de si mesmo, de uma identidade de auto-organização, do indivíduo (GALVANI, 1997, p. 48).

Retomando a centralidade que a autoformação denota, Pineau e Marie-Michèle afirmam que os diferentes polos não podem ser entendidos singularmente. Neste sentido, não parece possível discutir a autoformação sem se evocar a ligação e as articulações possíveis e necessárias com a heteroformação, entendida como a formação recebida pelos outros, e a ecoformação, i.e, a aprendizagem que decorre da vida em sociedade (PINEAU \& MARIE-MICHÈLE, 2012, p. 9). De fato, embora autoformação e heteroformação sejam vulgarmente tidos como conceitos opostos, como acontece aliás com as modalidades de educação formal e não formal/informal, não podem deixar de ser vistas como complementares. Nesta linha de ideias, Prévost argumenta que se registra "um sistema no qual o indivíduo definiria os seus objetivos e os seus meios. Neste caso, ninguém interviria e a autoformação seria uma construção de si"; paralelamente, verifica-se a possibilidade na qual "o indivíduo não teria qualquer ação sobre a sua própria formação, uma espécie de condicionamento, de adestramento, que poderia ser designado de heteroformação, um sistema racional no qual a aprendizagem foi pensada e facilitada pelo outro, pelos outros" (PRÉVOST, 1994, p. 35). Adicionalmente, a ecoformação, entendida como a relação que o sujeito estabelece com o mundo, não pode ser desprezada. A aprendizagem social, que decorre da vida no cotidiano, encontra-se profundamente influenciada pelas condições de vida dos sujeitos, bem como pela capacidade de os indivíduos enfrentarem e se confrontarem com os desafios que a experiência com os outros e consigo próprios envolve. É por esta razão o polo mais difícil de apreender, dado que se apresenta como fluído e fortemente articulado com os dois restantes polos. Remete 


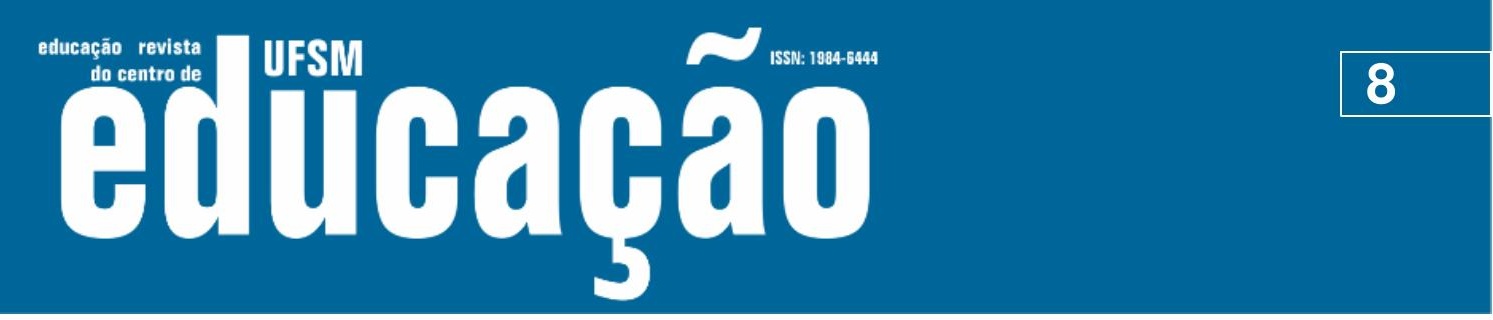

ISSN: 1984-6444 | http://dx.doi.org/10.5902/1984644461311

\section{Percurso metodológico}

Este texto tem origem num projeto que tem como propósito conhecer e compreender os percursos de educação e formação (ao longo da vida) dos sujeitos, assim como interpretar a complementaridade entre as modalidades formal, não formal e informal, e os processo de auto, hetero e ecoformação (GUIMARÃES \& FARIAFORTECOËF, 2013). Neste âmbito, a questão seguinte ganha relevância: como é que a educação formal, não formal e informal, assim como a auto, a hetero e a ecoformação se traduzem em aprendizagens? Esta questão é discutida a partir das interrogações que se seguem: como pensar a educação e formação e compreender os seus efeitos, tendo em consideração o olhar do sujeito sobre a sua vida, a sua visão do mundo, o seu sistema de representações, os seus valores (designadamente no quadro de narrativas autobiográficas)? Como compreender o papel da educação e da formação na vida dos indivíduos?

Este estudo inscreve-se numa abordagem qualitativa e compreensiva (LESSARD-HÉBERT, GOYETTE \& BOUTIN, 2005). Tem como método de pesquisa a investigação-formação, apresentando como finalidade "a consciencialização da experiência de vida" (GALVANI, 2006, p. 159). Utiliza as autobiografias como démarche para a unificação das atividades de educação, de investigação e de intervenção no próprio sujeito (PILON \& DESMARAIS, 1996, p. 12). Neste âmbito, foi preferida a autobiografia refletida ${ }^{1}$ (DESROCHE, 1990) como estratégia de coleta de dados, tendo envolvido duas etapas. A primeira etapa passou pela redação de duas autobiografias $^{2}$ consubstanciadas na reflexão sobre o percurso de vida educativo, assim como na tomada de consciência de aprendizagens desenvolvidas pelas inquiridas, a partir de três eixos: contexto (nacional, social e familiar); educação (formal, não formal e informal) e (auto, hetero e eco) formação; e experiência (profissional, extraprofissional). Ocasionalmente, foram levadas a cabo conversas informais sobre aspectos pontuais destas autobiografias que permitiram esclarecer dúvidas entretanto surgidas.

Uma das biografias foi escrita em francês no quadro de um percurso de ensino universitário, nomeadamente no decorrer da frequência de um mestrado ${ }^{3}$ realizado no 


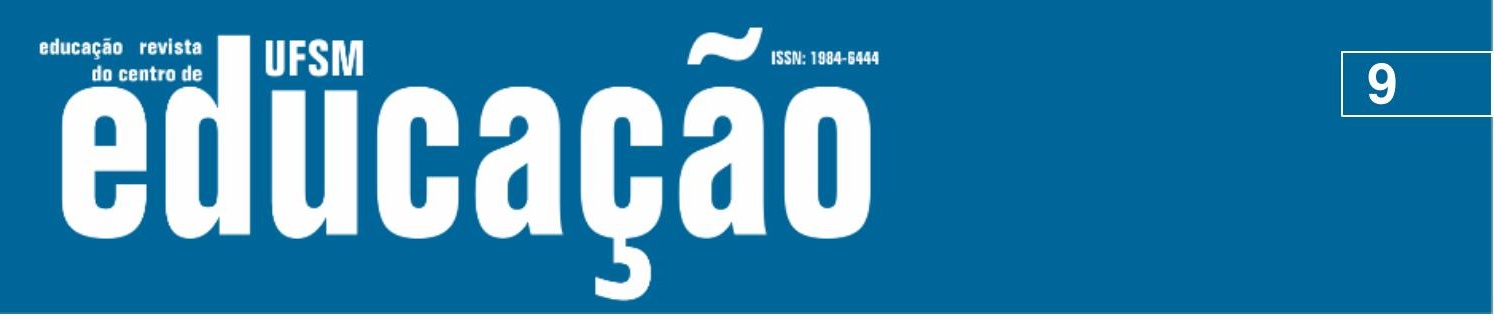

ISSN: 1984-6444 | http://dx.doi.org/10.5902/1984644461311

âmbito de um programa de formação profissional contínua ${ }^{4}$. Esta autobiografia centrou-se sobre as aprendizagens desenvolvidas ao longo da vida, nomeadamente em momentos em que a inquirida aprendeu a se conhecer melhor e a auto realizar-se (GALVANI, 2006). Este documento foi retomado no âmbito deste estudo, tendo sido revisto e traduzido para português. A segunda biografia foi redigida em língua portuguesa, a partir das mesmas orientações ${ }^{5}$. Deve-se ainda notar que estas narrativas foram redigidas em diferentes momentos de rememoração de etapas biográficas significativas, tendo como base de trabalho a importância desses tempos para os percursos de vida, nomeadamente no que remete para a educação, formal, não formal e informal, assim como a formação, ou seja, a auto, hetero e ecoformação (DESROCHE, 1990; JOSSO, 2008). Num segundo momento, estas histórias de vida foram sujeitas à interpretação, através da análise de conteúdo baseada em unidades de registro temáticas (educação/formação) e de contexto (nacional, social, familiar). Procurou-se identificar e compreender os modos como a auto, hetero e ecoformação foram apropriadas e relacionadas com a educação formal, não formal e/ou informal pelas inquiridas (FARIA-FORTECOËF, 2010; GUIMARÃES \& FARIA-FORTECOËF, 2013; FARIA-FORTECOËF \& GUIMARÃES, 2014).

Estas narrativas tiveram por base a subjetividade (DUBET, 1994), embora se tenha verificado a preferência por relatos descritivos, indicadores de momentos considerados relevantes por quem relatava a sua vida, pontuados por comentários de cariz reflexivo e analítico. É importante notar que estas duas autobiografias tiveram como pano de fundo a vaga de emigração que ocorreu nos anos de 1960 e 1970, uma vez que as inquiridas saíram ambas de Portugal nesse tempo. Este fato ganha outro significado se se pensar que se está perante sujeitos oriundos de grupos populares (LAHIRE, 2008), nos quais a educação formal muitas vezes se limitava à frequência de escolaridade obrigatória (então a 4⿳亠丷a classe), mas que, ao longo das suas vidas, efetuaram percursos de educação longos e ricos, em termos formais, não formais e informais nos quais a auto, a hetero e a ecoformação estiveram presentes. Neste âmbito, deve-se enfatizar que estes percursos foram o resultado de estratégias sociais assentes em projetos familiares (e não exclusivamente individuais) de cariz econômico, de prazos variáveis, "na procura de uma vida melhor"; de projetos de 


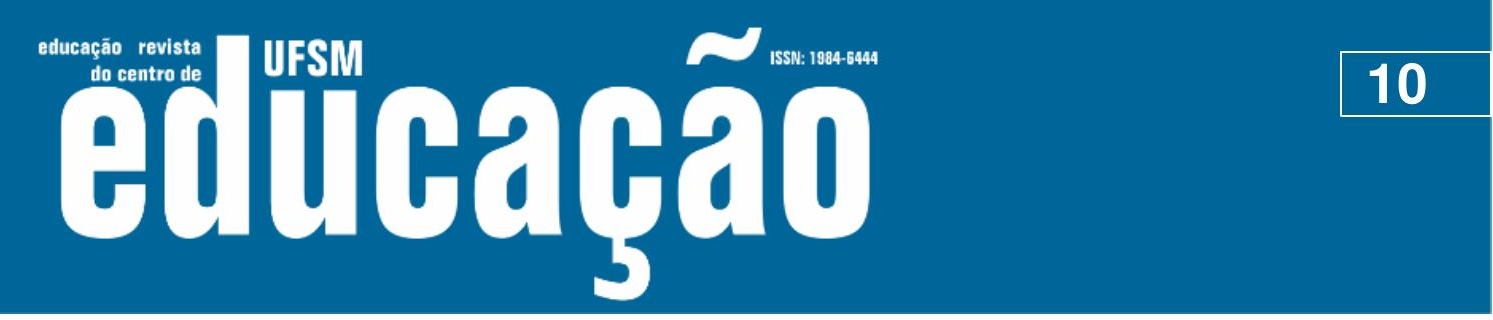

ISSN: 1984-6444 | http://dx.doi.org/10.5902/1984644461311

natureza cultural, "na busca de uma vida diferente" no caso das famílias de emigrantes, como aquelas às quais as inquiridas pertenciam (LEANDRO, 2004); bem como de projetos nas quais a iniciativa individual teve um papel importante (FARIAFORTECOËF, 2010). Os relatos obtidos, umas vezes mais sentidos que noutras, remetem para a história de Portugal nas últimas décadas, para o desenvolvimento das políticas educativas públicas e para o lugar social das classes populares (LAHIRE, 2008), como no caso dos emigrantes, em França, assim como aqueles que voltaram a Portugal. Estes relatos também destacam o local ocupado pela família e pelo trabalho (LEANDRO, 2004) na vida das inquiridas, bem como as transições biográficas inscritas em tempos incertos, como são os atuais. Foram narrativas que não deixaram de evidenciar uma procura de distanciamento dos sujeitos com as suas biografias, num esforço de objetividade, que foi mais evidente quando se tratou de pensar sobre eventos passados, e de subjetividade, no que envolveu outros acontecimentos mais recentes (ALHEIT \& DAUSIEN, 2006; JOSSO, 2008). Neste sentido, registrou-se um olhar do presente sobre o passado, num discurso centrado no eu, mas preocupado com as relações sociais e familiares e com os contextos nos quais ocorreram os acontecimentos relatados (BÉZILLE, 2006). Por último, note-se que na análise destas autobiografias foram considerados três momentos-chave do ato de autoformar-se, que se traduziram em aprendizagens diferenciadas: saber aprender, saber compreender e saber projetar-se (FARIA-FORTECOËF, 2010).

\section{As vidas de Júlia e Ana: um vaivém na educação (formal, não-formal e informal) e na (auto, hetero e eco) formação}

Júlia nasceu em 1962, numa cidade do Norte de Portugal, numa família ligada a quadros técnicos pouco qualificados: o avô era ourives, enquanto o pai trabalhava numa empresa nacional de gás e a mãe era doméstica. Esta família emigrou "a salto"6 e procurou na França, no início da década de 1970, "uma vida melhor", de resto uma ambição então comum a muitos outros emigrantes portugueses (LEANDRO, 2004). Já em França, o pai de Júlia esteve ligado temporariamente a empregos pouco qualificados, tendo mais tarde trabalhado numa fábrica, onde esteve até à sua 


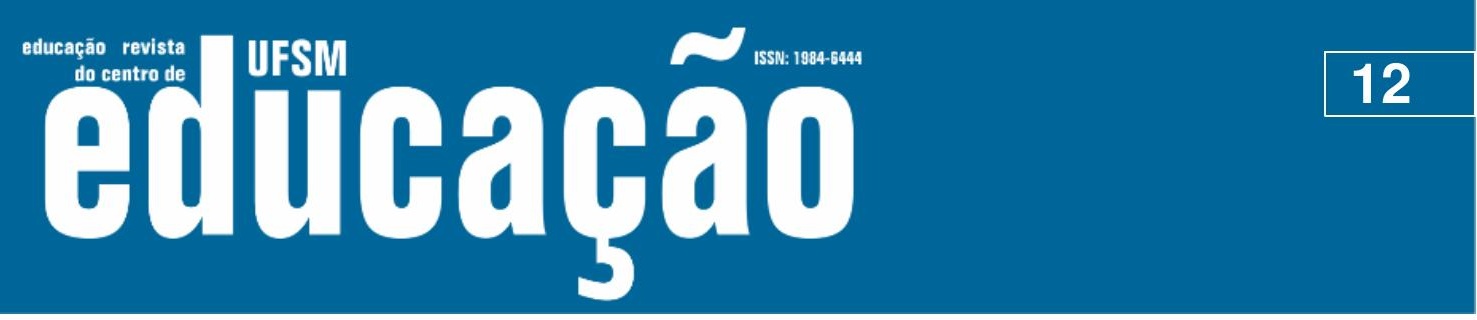

ISSN: 1984-6444 | http://dx.doi.org/10.5902/1984644461311

Tendo escolhido desde cedo a via da aprendizagem como uma filosofia de vida, o facto de certas pessoas com quem eu falava quando era mais nova não compreenderem que se aprende todos os dias, com tudo o que se faz e independentemente da idade, sempre me deixou perplexa. Tinha a impressão de ser um ser diferente, alguém que não sabia bem qual era o seu caminho e que não tinha outra coisa para fazer senão estudar. Também é verdade que em cada uma das minhas démarches se escondia uma questão que podemos considerar existencial: qual o meu lugar na sociedade, relativamente aos outros e relativamente a mim mesma?

Neste contexto, parece ter sido largamente ultrapassado o quadro escolar, como se verá em seguida, sendo igualmente relevantes para a inquirida as modalidades não formal e informal vivenciadas, em diversos processos de auto, hetero e ecoformação.

\section{Saber aprender}

Como referiu Rogers, "O indivíduo formado é aquele que aprendeu a aprender, a adaptar-se e a mudar, aquele que compreendeu que nenhum saber pode ser dado como certo e que só a capacidade de adquirir conhecimentos pode permitir um fundado sentimento de segurança" (ROGERS, 1976, p. 102). Este é um argumento importante no caso da educação, bem como da formação, uma vez que uma criança que aprende a aprender poderá tornar-se um adulto que consegue formar-se e, por essa via, construir um percurso de educação e formação (ao longo da vida). Tendo em consideração os dados recolhidos, parece que, desde cedo, Júlia e Ana compreenderam o significado da autoformação e da ecoformação, assim como da complementaridade destas com a heteroformação. De fato, ainda em Portugal, Júlia, no ensino primário, tinha bons resultados escolares e imaginava-se estudante em Coimbra ${ }^{8}$. Quando ingressou na escola em França, teve, no entanto, que voltar a frequentar o ensino primário, apesar da sua idade e de já ter concluído este ciclo de estudos no seu país de origem. Integrou então uma classe que incluía crianças três anos mais jovens que ela. Face a esta circunstância que decorria do seu parco domínio da língua francesa, desenvolveu uma estratégia de educação não formal, cruzado com a autoformação, através da qual aprendeu o idioma já referido, como foi pela mesma dito: 


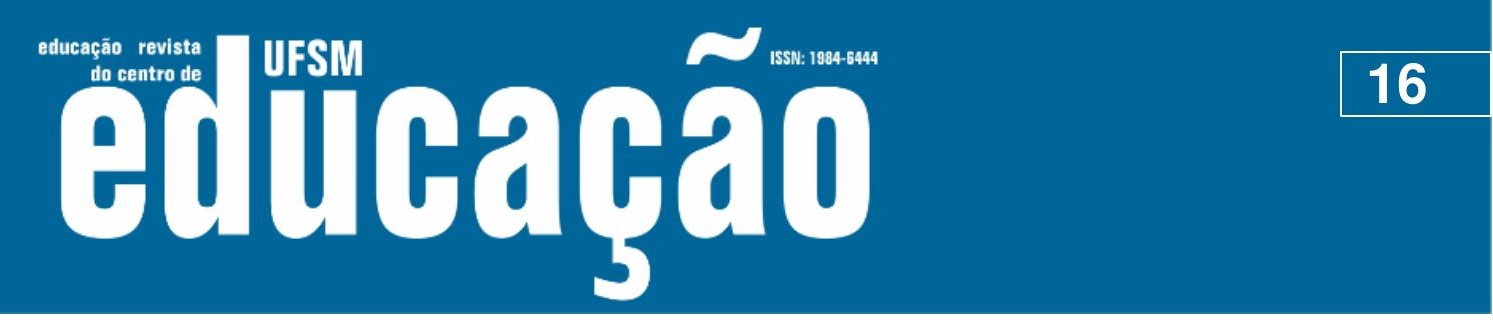

ISSN: 1984-6444 | http://dx.doi.org/10.5902/1984644461311

Esta necessidade, mas também este prazer pela aprendizagem, não significa a ausência de objetivo(s) claro(s), de promessa(s), na aceção de Ricoeur (1986), relativamente ao percurso de vida traçado num quadro formal. Pelo contrário, traduz a importância da iniciativa individual através do recurso à autonomia (PINEAU, 1988) em quadros educativos mais ou menos formalizados (FARIA-FORTECOËF, 2010). Nesta linha de ideias, Ana concluiu a Licenciatura e, depois de alguns empregos, foi contratada como professora de inglês numa escola. Este acontecimento e o que aprendeu com ele levou-a a pensar em encontrar a ligação educativa (CIFALLI, 1998), i.e., oportunidades de educação formal, assim como de educação não formal e informal, que de alguma forma legitimassem o que acabou por se tornar numa opção de vida. Assim, passou a ser capaz de identificar necessidades de educação e formação no seu percurso e a encontrar formar de solucioná-las:

Era professora de inglês. Estava a dar razão à minha mãe que sempre quis que eu fosse professora. $E$ devo dizer que, contrariamente ao que eu esperava, gostei do trabalho de ensinar. O ensino, a relação com os alunos (...). Logo percebi que não poderia continuar o resto da minha vida com a graduação que tinha, que devia formar-me como professora para poder assegurar o posto de trabalho. Tinha que igualmente aprender sozinha novos conhecimentos para resolver os problemas que ia enfrentando no dia-a-dia.

Pelo seu lado, Júlia afirmou:

Aprender é sentir-me totalmente presente num mundo em constante mudança. Aprender permite-me, sem dúvida, responder melhor às mudanças e pôr em questão todas as certezas que me impedem de avançar e de enfrentar os imprevistos ou o inesperado. Não conheço outra forma de perspetivar e de construir o meu futuro com a maior serenidade possível.

Desta forma, tanto para Ana como para Júlia, a escola e, mais amplamente a educação (incluída aqui a formação profissional) e a (auto e eco) formação, foram consideradas importantes para construírem os seus lugares no mundo (LAHIRE, 2008). Se a primeira identificou a sua profissão a partir da experiência de vida indicada atrás, para a segunda, foi no seio da sua família que essa possibilidade emergiu, mais tarde, na sequência das dificuldades sentidas na disciplina de francês pela sua própria filha: 


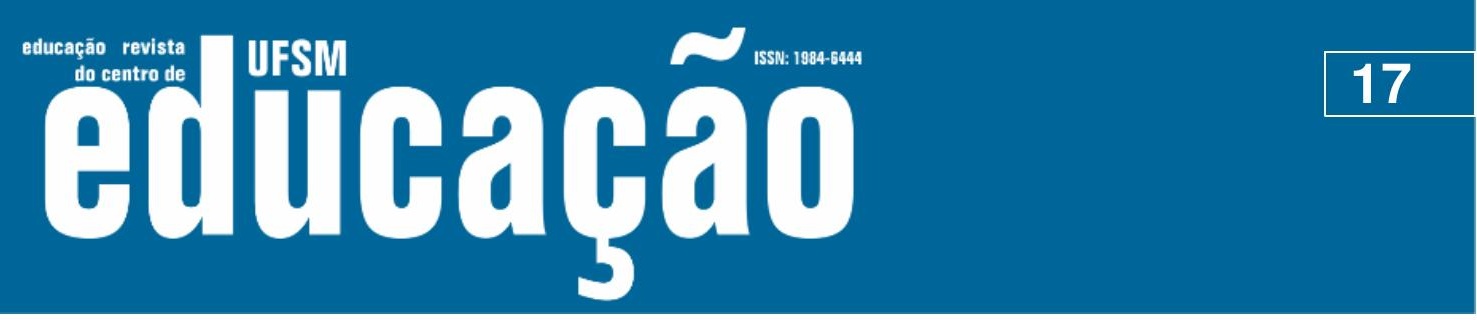

ISSN: 1984-6444 | http://dx.doi.org/10.5902/1984644461311

Depois de compreender a situação [de insucesso escolar] da minha filha e com a ajuda do professor dela de francês, procurei perceber onde estava o problema. Era um problema de compreensão, de trabalho, de metodologia? Num primeiro momento, interessei-me pelo programa de francês, pelas leituras, pelos exercícios pedidos. Depois, trabalhámos, a minha filha e eu, alternando trabalho de equipa com trabalho individual. Progressivamente, pudemos identificar o problema, que era de metodologia. Concentrei-me então no ato de aprender, no método mais adaptado e nos instrumentos pedagógicos a utilizar. E aí, a via que eu procurava - consciente ou inconscientemente - havia tanto tempo ficou clara. Ao ensinar a minha filha a aprender, senti-me no meu lugar; eu podia dar, transmitir e partilhar. Em troca, eu recebia outros saberes que pude integrar e transformar antes de poder mesmo transmitir-lhe esses conhecimentos. A ideia de que esta experiência se podia reproduzir com outras pessoas transportou-me literalmente para uma ótica de projeto de vida. Ensinar era a solução lógica, que me enriquecia sempre com novos saberes que me permitiam ver o mundo de outra forma.

Neste sentido, estas duas autobiografias inscrevem-se em diferentes modalidades educativas, através das quais se solucionam dificuldades encontradas, mas também enquanto esferas de desenvolvimento pessoal e social, i. e., de (auto, hetero e eco) formação (PINEAU, 1988). Nestes dois casos, o importante parece ser "a procura da causa ou da razão não só dos insucessos, mas também dos sucessos" (REBOUL, 1999, p. 83), dado que "o ato de compreender compromete o pensamento na dimensão da intersubjetividade que advém da singularidade, pois ele é tão somente a reconstrução parcial e parcelar de um sentido que faltava" (CIFALI, 1998, p. 51). Neste âmbito, a autoformação ganhou importância ao permitir que as inquiridas se distanciassem dos momentos vivenciados, refletissem sobre as suas condições de vida e opções biográficas, escolhessem caminhos que poderiam permitir maior autonomização e emancipação. Neste sentido, procuraram na autoformação dinâmicas reflexivas e de apropriação do poder da formação (PINEAU, 1988). Mesmo se ainda hoje estas inquiridas vivem na atualidade fases de transição, marcadas por dúvidas e incertezas quanto às suas profissões e ao futuro, elas não deixam de perspectivar os obstáculos como oportunidades de desenvolvimento de novas aprendizagens profissionais e pessoais, através de modalidades educativas formais, não formais e informais. A educação e a formação, nas suas várias modalidades e polos, inscrevem-se nos seus percursos de vida vistos em termos de soluções biográficas (ALHEIT \& DAUSIEN, 2006). De fato, nestes percursos, a complementaridade entre educação (formal, não formal e informal) e da (auto, hetero 


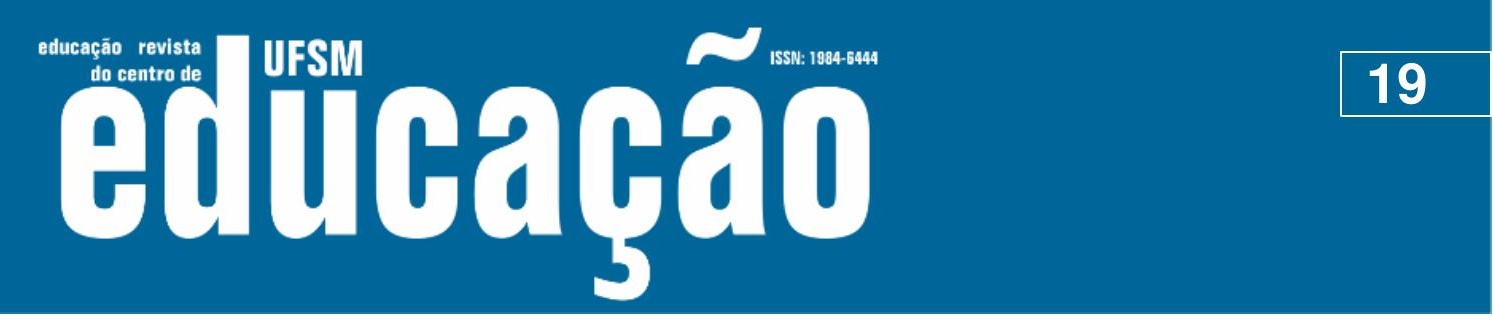

ISSN: 1984-6444 | http://dx.doi.org/10.5902/1984644461311

tempos vivenciados e oportunidades concedidas pela vida (BÉZILLE, 2006, p. 139). A preferência por autobiografias que incidem sobre a educação e a formação traduziu uma forte aposta na reflexividade; envolveu igualmente uma démarche que permite destacar os processos formais vividos pela experiência, mas sobretudo iluminar processos (formais, não formais e informais) responsáveis por muito do que os sujeitos sabem, como agem e refletem. Neste âmbito, são de enfatizar as apropriações de processos de autoformação, hetero e ecoformação, num esforço de consciencializar a experiência vivenciada (GALVANI, 2006) e de produzir as suas próprias vidas (VASSILEFF, 1995; PINEAU \& MARIE-MICHÈLE, 2012).

\section{Referências}

ALHEIT, Peter \& DAUSIEN, Bettina. Processo de formação e aprendizagens ao longo da vida. Educação e Pesquisa, vol.32, n.1, p. 177-197, 2006.

BEZILLE, Hélène. Du témoignage au travail sur les représentations. In Hélène Bézille e Bernardette Courtois, Dirs., Penser la relation expérience-formation. Lyon: Chronique Sociale, 2006.

CANÁRIO, Rui. Educação de Adultos. Um Campo, uma Problemática. Lisboa: EDUCA, 1999.

CANÁRIO, Rui. Aprender sem ser ensinado. A importância estratégica da educação não formal. In: AAVV, Educação em Portugal (1986-2006): alguns contributos de investigação. Lisboa: Conselho Nacional de Educação, 2006.

CAVACO, Cármen. Adultos pouco escolarizados. Políticas e práticas de formação. Lisboa: Educa, 2009.

CIFALI, Mireille. Le lien éducatif: contre-jour psychanalitique. Paris: PUF, 1998.

COOMBS, Philip H. Non-formal education: myths, realities, and opportunities. Comparative Education Review, vol. 20, n.ำ 3, p. 281-293, 1976.

DESROCHE, Henri. Entrependre d'apprendre: de l'autobiographie raisonnée aux projets d'une recherche-action. Paris: Ed. Ouvrières, 1990.

DUBET, Claude. Sociologie de l'éxpérience. Paris: Seuil, 1994.

FARIA-FORTECÖEF, Clarisse. Formation tout au long de la vie en Europe. Approche comparée exploratoire centrée sur l'iniciative individuelle: le cas de la France et du Portugal. Paris: Université Paris VIII - Vincennes Saint-Denis, 2010. 


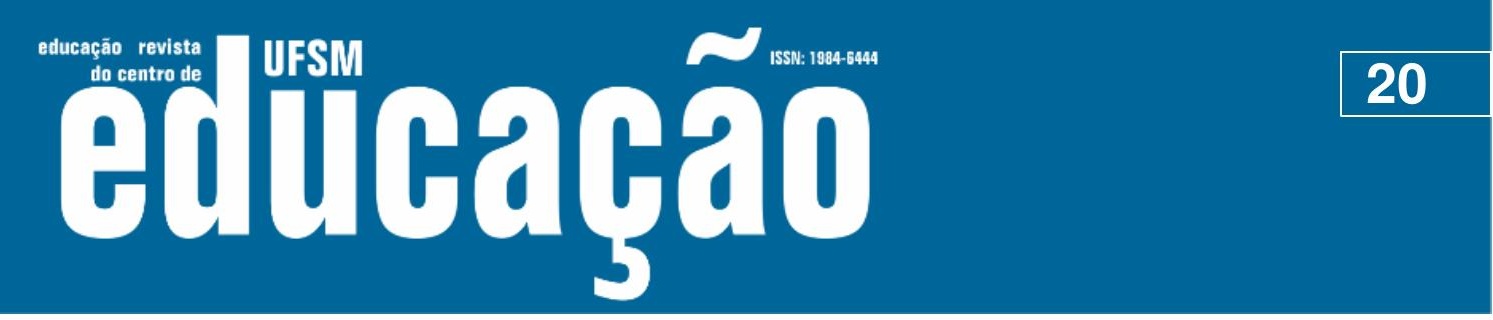

ISSN: 1984-6444 | http://dx.doi.org/10.5902/1984644461311

FARIA-FORTECÖEF, Clarisse \& GUIMARÃES, Paula. L'initiative individuelle en education et formation: une posture face à l'improbable? Chemins de Formation. Au Fils du Temps, n.ำ 18, p. 89-94, 2014.

FAURE, Edgar (Dir.), HERRERA, Felipe, KADDOURA, Abdul-Razzak, LOPES, Henri, PETROVSKI, Arthur V., RAHNEMA, Majid \& WARD, Frederick Champion. Aprender a ser. Lisboa: Livraria Bertrand, 1981.

GALVANI, Pascal. Quête de sens et formation: anthropologie du blason et de l'autoformation. Paris, Montréal: L'Harmattan, 1997.

GALVANI, Pascal. La conscientisation de l'expérience vécue: ateliers pour la recherche-formation. In : BEZILLE, Hélène e COURTOIS, Bernardette, Dir., Penser la relation expérience-formation. Lyon : Chronique Sociale, 2006.

GAULEJAC, Vincent de. La névrose de classe. Paris : Editions Hommes et Groupes, 1999.

GUIMARÃES, Paula. Políticas de educação de adultos (1999-2006). A emergência da educação e formação para a competitividade. Braga: Instituto de EducaçãoCied, 2011.

GUIMARÃES, Paula \& FARIA-FORTECÖEF, Clarisse. A educação como um dever e uma filosofia de vida: trajetórias educativas atípicas no contexto de emigração. In: PALHARES, José Augusto; AFONSO, Almerindo Janela (Orgs.), 0 não-formal e o informal em educação: centralidades e periferias. Atas do I Colóquio Internacional de Ciências da Educação. III Encontro de Sociologia da Educação. Braga: Universidade do Minho/Cied, 2013.

JOSSO, Marie-Christine.Formação de adultos: aprender a viver e a gerir mudanças. In CANÁRIO, Rui e CABRITO, Belmiro (Orgs.), Educação e formação de adultos. mutações e convergências. Lisboa: Educa, 2008.

LAHIRE, Bernard. Sucesso escolar nos meios populares. As razões do improvável. São Paulo. Editora Ática, 2008.

LEANDRO, Maria Engrácia. Dinâmica social e familiar dos projetos migratórios - uma perspetiva analítica. Análise Social, XXXIX (170), p. 94-118, 2004.

LESSARD-HEBERT, Michelle; GOYETTE, Gabriel \& BOUTIN, Gérald. Investigação qualitativa. Fundamentos e práticas. Lisboa: Instituto Piaget, 2005.

LIMA, Licínio C. A educação de adultos em Portugal (1974-2004). In Canário, Rui; Cabrito, Belmiro (Orgs.), Educação e formação de adultos. mutações e convergências. Lisboa: Educa, 2008.

LIMA, Licínio C., Coord.; ESTÊVÃO, M. Lucas; MATOS, Lisete; MELO, Alberto \& MENDONÇA, Amélia. Documentos preparatórios III. Comissão de Reforma do Sistema Educativo. Lisboa: Ministério da Educação, 1988. 


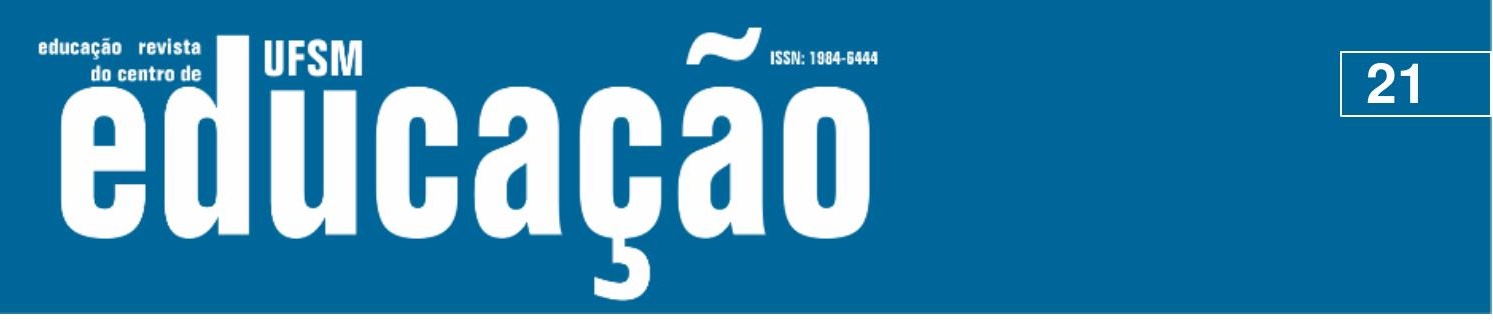

ISSN: 1984-6444 | http://dx.doi.org/10.5902/1984644461311

PALHARES, José Augusto (2009). Reflexões sobre o não-escolar na escola e para além dela. Revista Portuguesa de Educação, vol. 22, n.ำ 2, p. 53-84, 2009.

PILON, Jean-Marc \& DESMARAIS, Danielle. Les enjeux liés à la pratique des histoires de vie au carrefour de la formation des adultes, de la recherche et de l'intervention. In: Danielle Desmarais; Jean-Marc Pilon (Coords.), Pratiques des histoires de vie. Au carrefour de la formation, de la recherche et de l'intervention. Paris: L'Harmattan, 1996.

PINEAU, Gaston. A autoformação no decurso da vida: entre a hétero e a ecoformação. In M. Finger; A. Nóvoa (Orgs.), O método (auto)biográfico e a formação. Lisboa: Ministério da Saúde, 1988.

PINEAU, Gaston \& Marie-Michèle. Produire sa vie: autoformation et autobiographie. Paris: Téraèdre, 2012.

PREVOST, Hervé. L'individualisation de la formation: autonomie et-ou socialisation. Lyon: Chronique Sociale, 1994.

REBOUL, Olivier. Qu'est-ce qu'apprendre? Paris: PUF, 1999.

RICOEUR, Paul. Du texte à l'action. Paris: Éditions du Seuil, 1986.

ROGERS, Alan. The Bases of the Iceberg. Informal Learning and Its Impacts on Fornal and Informal Learning. Opladen: Barbara Budrich Publishers, 2014.

ROGERS, Carl. Liberté pour apprendre. Paris: Dunod, 1976.

TANGUY, Lucie. La fabrication d'un bien universel. In Guy Brucy, Pascal Caillaud, In: Quenson, Emmanuel; Tanguy, Lucie, Former pour réformer. Retour sur la formation permanente (1945-2004). Paris: La Découverte, 2007.

UNESCO. Recomendação sobre o desenvolvimento da educação de adultos aprovada pela Conferencia Geral da UNESCO na sua décima nona reunião. Nairobi, 26 de novembro de 1976. Braga: Universidade do Minho/Projecto de Educação de Adultos, 1977.

UNESCO. V Conferência internacional de educação de adultos. Lisboa: Ministério da Educação, 1998.

UNESCO. Recommendation on Adult Learning and Education 2015. Hamburgo: UNESCO Institute for Lifelong Learning, 2016.

VASSILEF, Jean. Histoires de vie et pédagogie du projet. Lyon: Chronique Sociale, 1999. 


\section{N

ISSN: 1984-6444 | http://dx.doi.org/10.5902/1984644461311

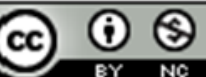

\section{This work is licensed under a Creative Commons Attribution-NonCommercial 4.0 International (CC BY-NC 4.0)}

\section{Notas}

\footnotetext{
${ }^{1}$ Em francês, Desroche (1990) designa esta narrativa de autobiographie raisonnée.

${ }^{2}$ Os nomes das inquiridas são fictícios.

${ }^{3}$ Em francês, este mestrado possui a seguinte designação: diplôme universitaire de formateurs d'adultes (DUFA).

${ }^{4}$ Em francês, congé individuel de formation $(C I F)$.

${ }^{5}$ As duas narrativas foram numa nova etapa sistematizadas numa grelha que incluiu os três eixos atrás indicados, inscritos numa linha cronológica.
}

${ }^{6}$ A emigração "a salto" caracterizou-se pelo fato de os emigrantes não possuírem documentos legais para poderem sair do país de origem. A passagem (ilegal) das fronteiras entre Portugal e Espanha e entre Espanha e França era feita por isso a pé e a correr - "a salto" -, em zonas de floresta e de mato.

${ }^{7}$ A cidade de Coimbra, em Portugal, possui a mais antiga universidade portuguesa, a Universidade de Coimbra, uma instituição de ensino superior histórica e muito prestigiada.

${ }^{8}$ Júlia é hoje docente do ensino superior, na categoria profissional de maître de conférences.

${ }^{9}$ La Bande à Picsou foi uma série de animação destinada a crianças muito popular em França, tendo sido emitida entre finais dos anos de 1980 e finais dos anos de 1990. Esta série foi igualmente editada em livros de banda desenhada.

${ }^{10}$ Ainda na década de 1970, em muitas escolas de educação básica, eram aplicados castigos corporais às crianças que tinham dificuldades de aprendizagem com uma régua ou uma palmatória de madeira.

${ }^{11}$ Títulos de canções populares que marcaram a Revolução Democrática que ocorreu em 1974, em Portugal. 